\title{
Autologous Peripheral Blood Stem Cell Transplantation Improves Portal Hemodynamics in Patients with Hepatitis B Virus-related Decompensated Cirrhosis
}

\author{
Qinzhi Deng,, ${ }^{1,2}$ Ting Cai, ${ }^{1}$ Shun Zhang, Airong Hu, Xingfen Zhang, ${ }^{1}$ Yinyin Wang, and \\ Jianrong Huang ${ }^{2, *}$ \\ ${ }_{1}^{1}$ Department of Liver Disease, Ningbo No. 2 Hospital, Ningbo, China \\ ${ }^{2}$ State Key Laboratory for Diagnosis and Treatment of Infectious Disease, Collaborative Innovation Center for Diagnosis and Treatment of Infectious Diseases, First Affiliated \\ Hospital, School of Medicine, Zhejiang University, Hangzhou, China \\ ${ }^{*}$ Corresponding Author: Jianrong Huang, State Key Laboratory for Diagnosis and Treatment of Infectious Disease, Collaborative Innovation Center for Diagnosis and \\ Treatment of Infectious Diseases, The First Affiliated Hospital, School of Medicine, Zhejiang University, Hangzhou 310003, China. Tel: +86-57187236743, Fax: +86-57187236743, \\ E-mail: dqznbey@126.com; hzhuangchina@sina.com
}

Received 2015 August 18; Revised 2015 November 8; Accepted 2015 November 8

\begin{abstract}
Background: Chronic hepatitis B virus (HBV) infection may eventually lead to decompensated liver cirrhosis, which is a terminal illness. Objectives: The aim of this study was to investigate the therapeutic efficacy of autologous peripheral blood stem cell (APBSC) transplantation to improve portal vein hemodynamics in patients with HBV-related decompensated cirrhosis.

Patients and Methods: This prospective study included 68 hospitalized patients who were diagnosed with HBV-related decompensated cirrhosis. These patients were divided into two groups: the transplantation group included 33 patients, while the control group included 35. Both groups received conventional medical treatment simultaneously, and APBSC transplantation was performed on the patients in the transplantation group. We evaluated the effects of APBSC transplantation on postoperative liver function using the following indices: total bilirubin, serum prothrombin and albumin, spleen size, and portal vein hemodynamics. Postoperatively, all of the patients were followed up at 24,36 , and 48 weeks.

Results: The transplantation group had no serious reactions. Compared with the control group, albumin and prothrombin activity in the transplantation group was significantly improved at 24,36, and 48 weeks after the procedure, and spleen length and portal vein diameter were substantially reduced at 48 weeks. The velocity of peak portal vein blood flow and mean maximum portal vein blood flow were greatly increased in the APBSC transplantation group at 36 and 48 weeks, respectively; however, there was also decreased portal vein diameter, which reduced portal vein pressure in patients with HBV-related decompensated cirrhosis.

Conclusions: APBSC transplantation greatly benefits HBV-linked decompensated cirrhosis patients and should be recommended in clinical practice.
\end{abstract}

Keywords: Portal Pressure, Liver Cirrhosis, Stem Cell Transplantation, Hepatitis B

\section{Background}

Chronic hepatitis B virus (HBV) infection may eventually lead to decompensated liver cirrhosis, which is a terminal illness. Decompensated cirrhosis is characterized by a number of complications, including ascites, hepatorenal syndrome, and upper gastrointestinal bleeding. These complications develop when the subject suffers from liver dysfunction that causes portal hypertension. Since the incidence of these complications is high, the disease is associated with a poor prognosis (1). Thus, cirrhosis requires medical therapy, which is mostly directed at relief of its complications. However, the efficacy of medical treatment, particularly for cirrhotic portal hypertension, is poor $(2,3)$. One of the major treatments for cirrhosis is the use of the nucleoside analogues of anti-HBV to suppress viral replication (anti-viral therapy). However, this medical approach cannot effectively reverse cirrhosis and portal hypertension in a short span of time. Thus, alternative effective treatments are needed for reducing portal hypertension and/or even reversing cirrhosis.

Recently, stem cell transplantation has been developed for the treatment of cirrhosis, which has achieved good improvement of liver function in some patients (4). The most commonly used stem cells are obtained from the umbilical cord, bone marrow, the liver itself, or peripheral blood (5-7). Peripheral blood stem cells exhibit numerous advantages, including convenient source, absence of rejection, simplicity of procedure, and low cost. A previous study showed that autologous peripheral blood stem cell (APBSC) transplantation improved liver function in HBV-linked liver cirrhosis

Copyright (C) 2015, Kowsar Corp. This is an open-access article distributed under the terms of the Creative Commons Attribution-NonCommercial 4.0 International License (http://creativecommons.org/licenses/by-nc/4.0/) which permits copy and redistribute the material just in noncommercial usages, provided the original work is properly cited. 
patients.6 However, whether APBSCs could attenuate portal hypertension, which is one of the major complications of liver cirrhosis, has not been investigated. The majority of studies on stem cell transplantation for the treatment of cirrhosis have observed liver function and Alb changes after transplantation.

\section{Objectives}

In the present study, we used APBSC transplantation to treat patients with decompensated HBV-linked cirrhosis, and explored the transplantation's impact on portal vein hemodynamics.

\section{Patients and Methods}

\subsection{Patients}

A total of 635 patients with HBV-related decompensated cirrhosis were treated at the Department of Liver Disease, Ningbo No. 2 Hospital, Zheijiang Province, China. This experimental study was conducted from July 2011 to December 2013. The diagnosis of cirrhosis was based on the 2009 version of the Acute-on-chronic Liver Failure: Consensus Recommendations of the Asia Pacific Association for the Study of Liver (APASL) (8) and Chronic Hepatitis B: Update 2009 by the American Association for the Study of Liver Diseases.1 The study was approved by the hospital's ethics committee.

The inclusion criteria were as follows: 1) age of $18-65$ years; 2) treatment for more than six months with nucleoside analog anti-HBV therapy, so that HBV DNA levels were $<10^{3} \mathrm{IU} / \mathrm{mL}$; and 3) no treatment with plasma, albumin, or other blood components for one month prior to enrolling in the study. The exclusion criteria included a medical history of any of the following: 1) cirrhosis caused by factors other than HBV (including hepatitis C/D virus infection, autoimmune liver disease, fatty liver, alcoholic liver disease, and genetic metabolic liver disease); 2) tumor; 3) primary or secondary renal disease or receiving renal replacement therapy; 4) severe cardiopulmonary disease or hemodynamic instability; 5) severe infection; 6) active bleeding; 7) coma; or 8) blood diseases. After applying the inclusion and exclusion criteria, 70 patients were included in the study. Before participating, all patients signed informed consent forms.

\subsection{Treatment Methods}

Seventy patients that met the inclusion criteria and agreed to enter the trial were assigned serial numbers. Among these patients, 35 agreed to undergo APBSC transplantation and were placed in the transplantation group. The remaining 35 received only conventional medical therapy, forming the control group. All patients received no other drugs or other treatments affecting portal vein hemodynamics, including propranolol, and HBV DNA levels were $<10^{3} \mathrm{IU} / \mathrm{mL}$ during the study. In the transplan- tation group, two patients were lost to follow-up during the 48-week follow-up period. Therefore, data analyses were performed on only 33 subjects from the transplantation group. Three days after receiving written consent from the patients, we began conducting this experimental study, and that time-point was used as the baseline.

Before undergoing APBSC transplantation, the patients received subcutaneous injections of granulocyte colonystimulating factor (G-CSF) for four days at a dosage of $400 \mu \mathrm{g} /$ day. The APBSCs were harvested on the second day after the fourth daily G-CSF injection by isolating 50 $\mathrm{mL}$ of stem cells from the peripheral blood using a blood cell separator. The $\mathrm{CD} 34^{+}$cell count was determined using flow cytometry. Purified stem cells $\left(2-4 \times 10^{7}\right)$ were administered to the hepatic artery via transfemoral catheterization within $2 \mathrm{~h}$ of purification. Both groups of patients received conventional medical treatment with nucleoside analogs administered in the form of entecavir (0.5 mg qd). All patients had received antiviral therapy for more than six months before they were enrolled in the study. The patients were also given silymarin and polyene phosphatidylcholine during the study to ensure liver protection. Thus, they received symptomatic and supportive treatment; however, no plasma, albumin, or other blood products were used during this period.

\subsection{Detection Methods, Instruments, and Reagents}

G-CSF was purchased from Kyowa Hakko Kirin Co., Ltd. (Shanghai, China). The COM.TEC blood cell separation instrument was purchased from Fresenius Kabi AG (Shanghai, China). The automatic biochemical analyzer and reagents were purchased from Beckman Coulter Commercial Enterprise Co., Ltd. (Beijing, China). The X300PE color Doppler ultrasound diagnostic apparatus was purchased from Siemens, Ltd. (Beijing, China). Before performing the test to assess portal hemodynamics, patients observed a fasting period of 8 hours. They were then placed in the supine position and asked to breathe quietly. Using the Siemens $\times 300$ PE color Doppler ultrasonic diagnostic apparatus, we measured the indices of portal hemodynamics, including the diameter of the portal vein (DPV), portal vein peak blood flow (PV$\max )$, and mean portal vein blood flow velocity ( $\left.\mathrm{PV}_{\text {mean }}\right)$. While carrying out this procedure, the apparatus was operated at a probe frequency of $3.5 \mathrm{MHz}$. To determine liver and kidney function, blood coagulation, and HBV DNA levels, all of the patients underwent routine blood tests. The patients in both groups were observed during a follow-up period of at least 48 weeks. Before (time 0 , baseline) performing the transplantation, we observed the patients' clinical symptoms, and at $12,24,36$, and 48 weeks after undergoing APBSC transplantation, we recorded any changes in these symptoms. We also noted changes in total bilirubin (TBil), albumin (Alb), prothrombin activity (PTA), spleen length and thickness, $\mathrm{DPV}, \mathrm{PV}_{\text {max }}$, and $\mathrm{PV}_{\text {mean }}$. 
Deng Q et al.

\subsection{Statistical Analysis}

EPI DATA software (China Center for Disease Control and Prevention, Chinese version, Beijing, China) was used for data entry and verification. SPSS statistical software version 13.0 (IBM Corp., Beijing, China) was used for data processing and analysis. The measured data was expressed in terms of mean \pm standard error of the mean (SEM). The paired-sample t test was used for performing intragroup comparisons, and the independent-sample t test was conducted for comparisons among groups. Homoscedasticity and normality tests were conducted; $t$ test was performed to assess homoscedasticity, while a non-parametric test was performed for identifying any abnormal distributions of the data. The $\mathrm{x}^{2}$ test was used to perform ratio comparisons. $\mathrm{P}<0.05$ was considered to be statistically significant.

\section{Results}

\subsection{Comparison Between Groups of Demographic and Basic Clinical Characteristics at Baseline}

Two patients were lost to follow-up because they moved to other areas, so only their 0-week data was collected during the 48-week follow-up period. Consequently, 68 patients were included in the study, with a median age of $49.85 \pm 10.77$ years (range 29 - 69 years). The 33 patients in the treatment group (20 males and 13 females) had a median age of $49.48 \pm 11.07$ years, and the 35 patients in the control group (23 males and 12 females) had a median age of $50.20 \pm 10.64$ years. Between the two groups, there were no significant differences before treatment in their demographic and basic clinical characteristics, such as age, sex, weight, TBil, Alb, PTA, spleen length and thickness, DPV, PVmax,$P V_{\text {mean }}$, or other indicators $(P>0.05)$ (Table 1$)$.

\subsection{Biochemical Index and MELD Score Changes after APBSC Transplantation}

There was no significant difference in TBil before and after transplantation or between the transplantation and control groups. Before transplantation, Alb was 30.10 $\pm 3.75 \mathrm{~g} / \mathrm{L}$, which significantly increased to $32.82 \pm 5.10$ $\mathrm{g} / \mathrm{L}, 34.02 \pm 3.60 \mathrm{~g} / \mathrm{L}$, and $34.70 \pm 3.80 \mathrm{~g} / \mathrm{L}$ at 24,36 , and 48 weeks after transplantation, respectively $(t=-2.79,-5.63$, and -6.66 , respectively; $\mathrm{P}<0.05)$. The differences in Alb were also significant compared with the control group at the same time-points ( $\mathrm{t}=2.68,2.93$, and 3.61, respectively; $\mathrm{P}<0.01)$. PTA also increased significantly to $53.39 \pm 9.20 \%$, $55.58 \pm 9.53 \%, 57.39 \pm 7.44 \%$, and $58.15 \pm 8.11 \%$ at $12,24,36$, and 48 weeks after transplantation, respectively $(\mathrm{t}=-2.53,-3.22$, -5.73 , and $-6.30 ; \mathrm{P}<0.05)$. In the transplantation group, the increased parameters at each time-point were significantly different from the control group $(t=-2.17,2.95$ and 3.78 , respectively; $\mathrm{P}<0.05)$. At 48 weeks after transplantation, the Model for End-stage Liver Disease (MELD) score was $11.30 \pm 3.08$ in the transplantation group. These values were significantly different from those observed before transplantation in the experimental group $(t=-2.99$, $\mathrm{P}<0.01)$. The MELD scores for the transplantation group were also significantly different from those of the control $\operatorname{group}(\mathrm{t}=2.43, \mathrm{P}<0.05)$ (Table 2$)$.

\begin{tabular}{|c|c|c|c|c|c|c|c|c|c|c|c|c|c|c|}
\hline Group & $\begin{array}{l}\text { Number } \\
\text { ofcases, } n\end{array}$ & Male & Female & Age, y & $\begin{array}{c}\text { Weight, } \\
\text { Kg }\end{array}$ & CTP & $\begin{array}{c}\text { TBil, } \\
\mu \mathrm{mol} / \mathrm{L}\end{array}$ & $\operatorname{Alb}(\mathrm{g} / \mathrm{L}$ & PTA, \% & $\begin{array}{c}\text { Spleenthickness, } \\
\text { mm }\end{array}$ & $\begin{array}{c}\text { Spleen } \\
\text { length, } \mathrm{mm}\end{array}$ & $\begin{array}{l}\text { DPV, } \\
\text { mm }\end{array}$ & $\begin{array}{c}\text { PV- } \\
\text { max' } \\
\text { cm/s }\end{array}$ & $\begin{array}{c}\mathrm{PV}_{\text {mean }} \\
\mathrm{cm} / \mathrm{s}\end{array}$ \\
\hline $\begin{array}{l}\text { Transplantation } \\
\text { Group }\end{array}$ & 33 & 20 & 13 & $\begin{array}{c}49.48 \pm \\
11.07\end{array}$ & $\begin{array}{c}58.7 \pm \\
7.02\end{array}$ & $\begin{array}{c}8.88 \pm \\
1.27\end{array}$ & $\begin{array}{l}55.20 \pm \\
38.95\end{array}$ & $\begin{array}{c}30.10 \pm \\
3.75\end{array}$ & $\begin{array}{c}50.0 \pm \\
6.56\end{array}$ & $48.30 \pm 9.38$ & $149.36 \pm 24.56$ & $\begin{array}{c}12.0 \pm \\
1.00\end{array}$ & $\begin{array}{c}18.6 \pm \\
3.22\end{array}$ & $15.7 \pm 3.41$ \\
\hline Control group & 35 & 12 & 23 & $\begin{array}{c}50.20 \\
\pm 10.64\end{array}$ & $\begin{array}{l}57.6 \pm \\
11.06\end{array}$ & $\begin{array}{c}9.34 \pm \\
0.64\end{array}$ & $\begin{array}{l}60.24 \pm \\
35.56\end{array}$ & $\begin{array}{c}28.75 \pm \\
8.20\end{array}$ & $\begin{array}{l}46.7 \pm \\
10.32\end{array}$ & $47.86 \pm 9.94$ & $150.57 \pm 23.46$ & $\begin{array}{c}12.0 \pm \\
0.92\end{array}$ & $\begin{array}{c}19.41 \pm \\
3.80\end{array}$ & $16.0 \pm 4.42$ \\
\hline Statistical value & & 0.19 & 0.19 & -0.27 & 0.54 & 1.89 & -0.98 & 0.86 & 1.57 & 0.19 & -0.21 & 0.14 & -0.94 & -0.25 \\
\hline PValue & & 0.66 & 0.66 & 0.78 & 0.59 & 0.07 & 0.33 & 0.38 & 0.12 & 0.85 & 0.84 & 0.89 & 0.35 & 0.81 \\
\hline
\end{tabular}

Table 2. Liver Function Parameters and Changes in Prothrombin Activity Before and After Treatment ${ }^{\mathrm{a}}$

\begin{tabular}{|c|c|c|c|c|c|c|}
\hline Group & o-Week & $12^{\text {th }}$ Week & $24^{\text {th }}$ Week & $36^{\text {th }}$ Week & $48^{\text {th }}$ Week & Number \\
\hline Treatment group & & & & & & 33 \\
\hline TBil, mol/L & $55.20 \pm 38.95$ & $54.33 \pm 34.34$ & $53.31 \pm 36.93$ & $56.35 \pm 32.70$ & $52.52 \pm 33.29$ & \\
\hline $\mathrm{Alb}, \mathrm{g} / \mathrm{L}$ & $30.10 \pm 3.75$ & $31.46 \pm 4.23$ & $32.82 \pm 5.10^{b}$ & $34.02 \pm 3.60^{b}$ & $34.70 \pm 3.80^{b}$ & \\
\hline PTA, \% & $50.09 \pm 6.56$ & $53.39 \pm 9.20^{b}$ & $55.58 \pm 9.53^{b}$ & $57.39 \pm 7.44^{b}$ & $58.15 \pm 8.11^{b}$ & \\
\hline MELD score & $12.94 \pm 1.92$ & $12.27 \pm 3.63$ & $12.12 \pm 3.41$ & $12.12 \pm 3.13$ & $11.30 \pm 3.08^{C}$ & \\
\hline Control group, & & & & & & 35 \\
\hline TBil, mol/L & $60.24 \pm 35.56$ & $56.63 \pm 30.44$ & $55.89 \pm 36.07$ & $57.18 \pm 28.69$ & $55.23 \pm 31.32$ & \\
\hline Alb, g/L & $28.75 \pm 8.20$ & $29.11 \pm 6.19$ & $29.16 \pm 6.13^{d}$ & $30.87 \pm 5.11^{\mathrm{d}}$ & $30.58 \pm 5.43^{\mathrm{d}}$ & \\
\hline PTA, \% & $46.77 \pm 10.32$ & $48.09 \pm 10.87$ & $48.29 \pm 10.78^{C}$ & $50.34 \pm 7.91^{C}$ & $50.09 \pm 8.01^{C}$ & \\
\hline MELD score & $13.57 \pm 1.96$ & $13.66 \pm 3.26$ & $13.43 \pm 3.24$ & $13.31 \pm 3.73$ & $13.31 \pm 2.44^{d}$ & \\
\hline
\end{tabular}

\footnotetext{
${ }^{\mathrm{a}}$ Values are presented as mean \pm SD.

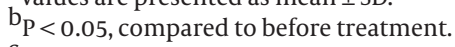

$\mathrm{C}_{\mathrm{P}}<0.01$, compared to the control group.
}

$\mathrm{d}_{\mathrm{P}}<0.05$, compared to the control group. 


\subsection{Reduced Spleen Length After APBSC Transplan- tation}

Before transplantation, there was no significant difference in spleen thickness between the transplantation and control groups $(\mathrm{P}>0.05)$. However, eight weeks after the transplantation, spleen length decreased from 149.36 $\pm 24.56 \mathrm{~mm}$ to $139.55 \pm 24.12 \mathrm{~mm}$ in the transplantation group ( $\mathrm{t}=-2.21, \mathrm{P}<0.05)$, which was significantly different from the spleen length of $151.66 \pm 19.76 \mathrm{~mm}$ that was observed in the control group $(\mathrm{t}=-2.27, \mathrm{P}<0.05)$ (Table 3$)$.

\subsection{Improved Portal Vein Hemodynamics after APBSC Transplantation}

At 36 and 48 weeks after transplantation, DPV measurements in the transplant group were $11.42 \pm 1.30 \mathrm{~mm}$ and $11.21 \pm 1.05 \mathrm{~mm}$, respectively. These values were significantly different from those observed before transplantation in this group $(t=2.26$ and $3.44, P<0.05)$. The DPV values were also significantly different from those of the control group $(\mathrm{t}=2.70$ and $3.25, \mathrm{P}<0.05)$. At 36 and 48 weeks after transplantation, $\mathrm{PV}_{\max }$ values were $20.43 \pm$ $2.42 \mathrm{~cm} / \mathrm{s}$ and $20.03 \pm 2.51 \mathrm{~cm} / \mathrm{s}$, respectively, which were significantly different from $18.61 \pm 3.22 \mathrm{~cm} / \mathrm{s}$, observed before transplantation $(\mathrm{t}=-3.24, \mathrm{P}<0.01 ; \mathrm{t}=-2.35, \mathrm{P}<0.05)$; these DPV values also significantly differed from those of the control group $(\mathrm{t}=2.12, \mathrm{P}<0.05 ; \mathrm{t}=2.37, \mathrm{P}<0.05)$. At 36 and 48 weeks after transplantation, $\mathrm{PV}_{\text {mean }}$ values were $17.54 \pm 3.16 \mathrm{~cm} / \mathrm{s}$ and $17.84 \pm 3.40 \mathrm{~cm} / \mathrm{s}$, respectively, differing significantly from the $\mathrm{PV}_{\text {mean }}$ value of $15.78 \pm 3.41 \mathrm{~cm} / \mathrm{s}$ that was observed before transplantation in the experimental group $(\mathrm{t}=-2.28, \mathrm{P}<0.05 ; \mathrm{t}=-2.54, \mathrm{P}<0.05)$. These values were also different from those observed in the control group $(\mathrm{t}=2.57, \mathrm{P}<0.05 ; \mathrm{t}=2.60, \mathrm{P}<0.05)$ (Table 4).

\subsection{Changes in Clinical Symptoms, Signs, and Child-Turcotte-Pugh (CTP) Score}

There were no deaths during this experiment, and no fever, bleeding, or other adverse events were detected in these patients. Moreover, according to the results of the B-ultrasound examinations, no signs of hepatic carcinoma were detected in any patient after successfully undergoing transplantation. There were no statistical differences in CTP scores before transplantation between the two groups $(\mathrm{P}>0.05)$ (Table 1$)$. At 48 weeks after the transplantation, CTP scores decreased from $8.88 \pm 1.27$ to $7.67 \pm 0.99$ in the transplantation group $(\mathrm{t}=6.80, \mathrm{P}<$ 0.01), differing significantly from the CTP scores of 9.09 \pm 2.59 observed in the control group $(\mathrm{t}=-3.00, \mathrm{P}<0.01)$.

\begin{tabular}{|c|c|c|c|c|c|c|}
\hline Group & o Week & $1^{\text {th }}$ Week & $24^{\text {th }}$ Week & $36^{\text {th }}$ Week & $48^{\text {th }}$ Week & Number \\
\hline Treatment group & & & & & & 33 \\
\hline Spleen length, mm & $149.3 \pm 24.56$ & $147.42 \pm 21.82$ & $143.73 \pm 21.71$ & $143.73 \pm 23.08$ & $139.55 \pm 24.12^{\mathrm{a}, \mathrm{b}}$ & \\
\hline Spleen thickness, mm & $48.30 \pm 9.38$ & $47.42 \pm 10.21$ & $48.36 \pm 10.85$ & $47.42 \pm 9.86$ & $45.49 \pm 10.83$ & \\
\hline Control group & & & & & & 35 \\
\hline Spleen length, mm & $150.57 \pm 23.46$ & $151.14 \pm 23.09$ & $150.11 \pm 19.30$ & $150.26 \pm 18.27$ & $151.66 \pm 19.76$ & \\
\hline Spleen thickness, mm & $47.86 \pm 9.94$ & $48.06 \pm 9.33$ & $48.29 \pm 10.60$ & $48.11 \pm 8.87$ & $48.29 \pm 8.74$ & \\
\hline
\end{tabular}

$\mathrm{a}_{\mathrm{P}}<0.05$, compared to before treatment.

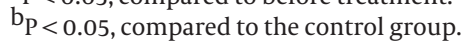

Table 4. Intragroup and Intergroup Comparisons of Peak Portal Vein Blood Flow and Mean Maximum Portal Vein Blood Flow Velocity of the two Groups Before and After Treatment

\begin{tabular}{|c|c|c|c|c|c|c|}
\hline Group & o Week & 12 $^{\text {th }}$ Week & $24^{\text {th }}$ Week & $36^{\text {th }}$ Week & $48^{\text {th }}$ Week & Number \\
\hline Treatment group & & & & & & 33 \\
\hline $\mathrm{DPV}, \mathrm{mm}$ & $12.06 \pm 1.00$ & $11.64 \pm 1.11$ & $11.73 \pm 1.31$ & $11.42 \pm 1.30^{\mathrm{a}, \mathrm{b}}$ & $11.21 \pm 1.05^{\mathrm{a}, \mathrm{b}}$ & \\
\hline $\mathrm{PV}_{\text {max }}, \mathrm{cm} / \mathrm{s}$ & $18.61 \pm 3.22$ & $19.17 \pm 3.08$ & $19.29 \pm 2.79$ & $20.43 \pm 2.42^{\mathrm{a}, \mathrm{b}}$ & $20.03 \pm 2.51^{\mathrm{a}, \mathrm{b}}$ & \\
\hline $\mathrm{PV}_{\text {mean }}, \mathrm{cm} / \mathrm{s}$ & $15.78 \pm 3.41$ & $16.54 \pm 2.84$ & $16.70 \pm 2.44$ & $17.54 \pm 3.16^{\mathrm{a}, \mathrm{b}}$ & $17.84 \pm 3.40^{\mathrm{a}, \mathrm{b}}$ & \\
\hline Control group & & & & & & 35 \\
\hline $\mathrm{DPV}, \mathrm{mm}$ & $12.03 \pm 0.92$ & $11.77 \pm 1.21$ & $11.86 \pm 1.17$ & $12.26 \pm 1.40$ & $12.14 \pm 1.29$ & \\
\hline $\mathrm{PV}_{\text {max }}, \mathrm{cm} / \mathrm{s}$ & $19.41 \pm 3.79$ & $19.47 \pm 2.37$ & $18.99 \pm 3.20$ & $18.89 \pm 3.45$ & $18.49 \pm 2.84$ & \\
\hline $\mathrm{PV}_{\text {mean }}, \mathrm{cm} / \mathrm{s}$ & $16.02 \pm 4.42$ & $16.49 \pm 2.84$ & $15.81 \pm 2.68$ & $15.72 \pm 2.67$ & $15.65 \pm 3.55$ & \\
\hline
\end{tabular}

${ }_{\mathrm{P}}<0.05$, compared to before treatment

$\mathrm{b}_{\mathrm{P}<0.05}$, compared to the control group. 


\section{Discussion}

In this study, we performed APBSC transplantation to treat patients with HBV-associated liver cirrhosis. After the operation, the patients were followed for 48 weeks. During the follow-up sessions, we found improvements in liver function and portal vein hemodynamics in the patients who had undergone transplantation. The spleen size and portal vein diameter reduced after transplantation; the blood flow in the portal vein also improved gradually, a remarkable achievement that we consistently observed during the follow-up period of 48 weeks. Thus, our findings indicate that it is advantageous to carry out APBSC transplantation in patients diagnosed with HBV-linked decompensated cirrhosis. Although several previous studies have described how liver cirrhosis can be treated with stem cell transplantation, those patients showed elevated levels of serum albumin after undergoing transplantation (9-11). However, one of the limitations of these previous studies was that the followup period was short (usually 12 - 24 weeks), and the transplantation was performed on a small number of patients. In our study, we also found that the level of circulating albumin increased significantly in patients subjected to APBSC treatment; however, these elevated levels lasted for up to 48 weeks postoperatively. In addition, in the APBSC treatment group, the prothrombin levels were significantly higher than in the control group. Since circulating albumin and prothrombin are sensitive indicators of hepatic function, an increase in the levels of these two proteins indicates an improvement in liver function. This finding agreed with the results of a previous report that described the use of APBSCs to treat liver cirrhosis (6).

Very few studies have investigated portal vein hemodynamics. Moreover, these studies were conducted for shorter time durations and used samples of smaller sizes (12). However, we have not come across any report that described the hemodynamic parameters of patients who underwent APBSC transplantation.

Activated hepatic stellate cells play an important role in the occurrence and development of liver fibrosis, which causes increased resistance to blood flow in the portal vein. In addition, increased serum NO, glucagon, $\mathrm{H}_{2} \mathrm{~S}$, and other factors may also induce portal vein vasoconstriction, thus contributing to the development of portal hypertension $(13,14)$. Portal hypertension is also associated with a higher incidence of complications and a poor prognosis. Thus, it is a major challenge that needs to be addressed when treating decompensated cirrhosis with our current approach. We have proven that APBSC transplantation improves portal vein hemodynamics, as we achieved decreased spleen size and DPV postoperatively. Thus, the blood flow rate in the portal vein was increased postoperatively. The potential mechanisms involved in this improvement are elaborated as follows: 1) the transplanted stem cells differentiate into liver cells, which replace/repair the damaged dysfunctional cells; 2 ) a paracrine mechanism promotes endogenous regeneration of hepatocytes and enhances immunomodulatory and antifibrotic activity $(15,16) ; 3)$ stem cell transplantation triggers apoptosis of hepatic stellate cells and ameliorates liver fibrosis (17); and 4) as shown in a previous study, APBSC transplantation can regulate serum NO, glucagon, $\mathrm{H}_{2} \mathrm{~S}$, and other factors (need reference). Thus, APBSC transplantation is beneficial for portal venous hemodynamics via multiple mechanisms.

In this study, after performing stem cell transplantation, we observed that serum levels of PTA and Alb were significantly increased at 12 and 24 weeks, respectively. Subsequently, within 36 weeks after transplantation, portal hemodynamics showed substantial improvement, with reduced spleen length at 48 weeks. Thus, decreased spleen length and improved portal hemodynamics were observed at later stages, while improved liver function was observed within a shorter time-interval postoperatively because degradation of the extracellular matrix takes a long time (i.e., reversing liver fibrosis is a slow process). Therefore, our observations indicate that stem cell transplantation diminishes liver fibrosis and probably improves portal hemodynamics as a consequence. In our previous study, we observed an improvement in liver reserve function following the recovery of liver synthetic function (6). Although we postulate that there are several potential mechanisms through which APBSC transplantation can benefit portal hemodynamics, we do not rule out the possibility of other mechanism(s). In addition, we need to investigate how long the improved portal hemodynamics are sustained in patients who have undergone APBSC transplantation.

Pathological examination of the liver is the gold standard for determining the degree of liver fibrosis. To precisely explore whether APBSC transplantation improves liver function by reversing fibrosis, we planned to examine the liver pathology before and after treatment in both of the groups. However, since the coagulation function of patients with decompensated cirrhosis is poor, liver biopsies probably would have caused bleeding. Therefore, we did not conduct liver biopsies in this study. Similarly, although the wedged hepatic vein pressure (WHVP) of portal blood flow is the best tool for identifying improvements in portal pressure, the risk of bleeding is quite high (18-20). Therefore, we used an indirect method (Bultrasound) to assess portal hemodynamics in this study. Furthermore, B-ultrasound is able to accurately evaluate changes in the blood flow of the portal vein system, including DPV and PV $_{\text {mean }}$, so it is widely used as a simple and reliable means for the appraisal of portal hemodynamics.10 However, a limitation of our study was the fact that we neither performed liver biopsy nor did we measure WHVP.

Currently, poor efficacy is observed with the drugs used for the treatment of portal hemodynamic abnormali- 
ties arising from liver cirrhosis. In this scenario, APBSC transplantation offers an alternative and efficient way to improve portal hemodynamics, relieve portal hypertension, and reduce the complications associated with portal hypertension. Thus, given its numerous benefits and easy operability, APBSC transplantation may be used for treating liver cirrhosis, and it is a promising candidate that can be adapted in clinical practice.

\section{Footnotes}

Authors' Contribution:Study concept and design: Qinzhi Deng, Jianrong Huang, and Ting Cai; analysis and interpretation of data: Airong Hu and Shun Zhang; drafting of the manuscript: Qinzhi Deng and Yinyin Wang; critical revision of the manuscript for important intellectual content: Qinzhi Deng and Jianrong Huang; statistical analysis: Xingfen Zhang.

Funding/Support:This study was funded by the Ningbo Science and Technology Innovation Team Project (No. 2011B82016).

\section{References}

1. Lok AS, McMahon BJ. Chronic hepatitis B: update 2009. Hepatology. 2009;50(3):661-2. doi:10.1002/hep.23190. [PubMed:19714720]

2. Garcia-Pagan JC, Caca K, Bureau C, Laleman W, Appenrodt B, Luca A, et al. Early use of TIPS in patients with cirrhosis and variceal bleeding. N Engl J Med. 2010;362(25):2370-9. doi:10.1056/NEJMoa0910102. [PubMed: 20573925]

3. Garcia-Tsao G, Sanyal AJ, Grace ND, Carey W, Practice Guidelines Committee of the American Association for the Study of Liver D, Practice Parameters Committee of the American College of G Prevention and management of gastroesophageal varices and variceal hemorrhage in cirrhosis. Hepatology. 2007;46(3):922-38. doi:10.1002/hep.21907. [PubMed:17879356]

4. Takami T, Terai S, Sakaida I. Stem cell therapy in chronic liver disease. Curr Opin Gastroenterol. 2012;28(3):203-8. doi: 10.1097| MOG.ob013e3283521d6a. [PubMed: 22395569]

5. Xu L, Gong Y, Wang B, Shi K, Hou Y, Wang L, et al. Randomized trial of autologous bone marrow mesenchymal stem cells transplantation for hepatitis B virus cirrhosis: regulation of Treg/Th17 cells. J Gastroenterol Hepatol. 2014;29(8):1620-8. doi: 10.1111/jgh.12653. [PubMed: 24942592]

6. Cai T, Deng Q, Zhang S, Hu A, Gong Q, Zhang X. Peripheral blood stem cell transplantation improves liver functional reserve. Med Sci Monit. 2015;21:1381-6. doi: 10.12659/MSM.892990. [PubMed: 25970080]

7. Kisseleva T, Gigante E, Brenner DA. Recent advances in liver stem cell therapy. Curr Opin Gastroenterol. 2010;26(4):395-402. doi 10.1097/MOG.0b013e32833a6bec. [PubMed: 20495456]
8. Sarin SK, Kumar A, Almeida JA, Chawla YK, Fan ST, Garg H, et al Acute-on-chronic liver failure: consensus recommendations of the Asian Pacific Association for the study of the liver (APASL) Hepatol Int. 2009;3(1):269-82. doi: 10.1007/s12072-008-9106-X. [PubMed: 19669378]

9. Nakamura T, Torimura T, Sakamoto M, Hashimoto O, Taniguchi $\mathrm{E}$, Inoue K, et al. Significance and therapeutic potential of endothelial progenitor cell transplantation in a cirrhotic liver rat model. Gastroenterology. 2007;133(1):91-107 e1. doi: 10.1053/j.gastro.2007.03.110. [PubMed: 17631135]

10. Peng L, Xie DY, Lin BL, Liu J, Zhu HP, Xie C, et al. Autologous bone marrow mesenchymal stem cell transplantation in liver failure patients caused by hepatitis B: short-term and long-term outcomes. Hepatology. 2011;54(3):820-8. doi: 10.1002/hep.24434. [PubMed: 21608000]

11. Terai S, Sakaida I, Nishina H, Okita K. Lesson from the GFP/CCl4 model-translational research project: the development of cell therapy using autologous bone marrow cells in patients with liver cirrhosis.J Hepatobiliary Pancreat Surg. 2005;12(3):203-7. doi: 10.1007/s00534-005-0977-0. [PubMed:15995808]

12. Shang JZ, Ma LF, Ma HW. Efect of autologous bone marrow derived mesenchymal stem cells on portal hemodynamics in patients with liver cirrhosis (in Chinese). J Clin Heptol. 2013;29(11):848-51.

13. Arruda SM, Barreto VS, Amaral FJ. Duplex sonography study in schistosomiasis portal hypertension: characterization of patients with and without a history of variceal bleeding. Arq Gastroenterol. 2008;45(1):11-6. [PubMed:18425222]

14. Maruyama H, Yokosuka O. Pathophysiology of portal hyperten sion and esophageal varices. Int J Hepatol. 2012;2012:895787. doi: 10.1155/2012/895787. [PubMed: 22666604]

15. Oh SH, Witek RP, Bae SH, Zheng D, Jung Y, Piscaglia AC, et al. Bone marrow-derived hepatic oval cells differentiate into hepatocytes in 2-acetylaminofluorene/partial hepatectomy-induced liver regeneration. Gastroenterology. 2007;132(3):1077-87. doi: 10.1053/j. gastro.2007.01.001. [PubMed:17383429]

16. Takeda M, Yamamoto M, Isoda K, Higashiyama S, Hirose M, Ohgushi $\mathrm{H}$, et al. Availability of bone marrow stromal cells in threedimensional coculture with hepatocytes and transplantation into liver-damaged mice. J Biosci Bioeng. 2005;100(1):77-81. doi: 10.1263/jbb.100.77. [PubMed:16233854]

17. Lin N, Hu K, Chen S, Xie S, Tang Z, Lin J, et al. Nerve growth factormediated paracrine regulation of hepatic stellate cells by multipotent mesenchymal stromal cells. Life Sci. 2009;85(7-8):291-5. doi:10.1016/j.lfs.2009.06.007. [PubMed: 19559033]

18. Bosch J. Carvedilol for preventing recurrent variceal bleeding waiting for convincing evidence. Hepatology. 2013;57(4):1665-7. doi:10.1002/hep.26279. [PubMed:23359118]

19. Gluud C, Brok J, Gong Y, Koretz RL. Hepatology may have problems with putative surrogate outcome measures. J Hepatol. 2007;46(4):734-42. doi: 10.1016/j.jhep.2007.01.003. [PubMed: 17316871]

20. Maleux G, Willems E, Fieuws S, Heye S, Vaninbroukx J, Laleman $\mathrm{W}$, et al. Prospective study comparing different indirect methods to measure portal pressure. J Vasc Interv Radiol. 2011;22(11):1553-8. doi:10.1016/j.jvir.2011.08.003. [PubMed: 22024115] 